\title{
Small-scale mining - hazards and opportunities in Kyrgyzstan and Mongolia
}

\author{
Peter W.U. Appel
}

Small-scale mining is the main source of income for about 100 million people in Asia, Africa and South America. However, the processing of raw materials during this mining activity results in the release of large amounts of mercury to the environment, creating serious environmental problems.

Small-scale mining, or artisanal mining, is exploitation using only shovels, picks and hammers, carried out by individuals or small groups. A wide variety of commodities are exploited in this way, ranging from gold, diamonds, precious stones, tin, coal, dimension stones and slate. Small-scale mining is often carried out by labourers with virtually no knowledge of safety procedures. Tunnel cave-ins leading to loss of life are common, and the widespread use of mercury in gold extraction causes many long-term health problems for the miners. It is estimated that about 650 tonnes of mercury are annually released during small-scale mining to the environment, and this figure is likely to increase in the future.

Mercury is highly toxic and its use causes health problems not only for the miners, but also to the entire population in areas where small-scale mining takes place. Some miners are aware of the dangers of using mercury, but have no knowledge of recycling procedures. Several international organisations, such as the World Bank, UNIDO (United Nations Industrial Development Organisation), ILO (International Labour Organisation) and UNDP (United Nations Development Programme), have launched programmes to examine the problems associated with small-scale mining. Progress so far has been slow, and much more international awareness of the global mercury pollution of the environment from smallscale mining is required. The Geological Survey of Denmark and Greenland (GEUS) has worked as consultant to the World Bank on projects involving small-scale mining in Kyrgyzstan, Mongolia and Laos, and has also undertaken programmes concerning small-scale mining in Lesotho for UNDP and in Tanzania for the Danish International Development Agency (DANIDA). This paper reports on some of the initiatives carried out in Kyrgyzstan and Mongolia, to secure and sustain the small-scale mining industry in these regions.

\section{A historical view}

Small-scale mining has been carried out since ancient times. Many know the legend of Jason and the Golden Fleece which may, in fact, be the first record of small-scale mining in the history of mankind. Herdsmen traditionally placed a ram's fleece in a river at springtime, which trapped gold particles tumbling down the river during the spring floods. After a month or so the fleece would be burned, or dried and shaken, to collect the gold grains. This ancient technique is still used by herdsmen in Kyrgyzstan to recover gold from streams.

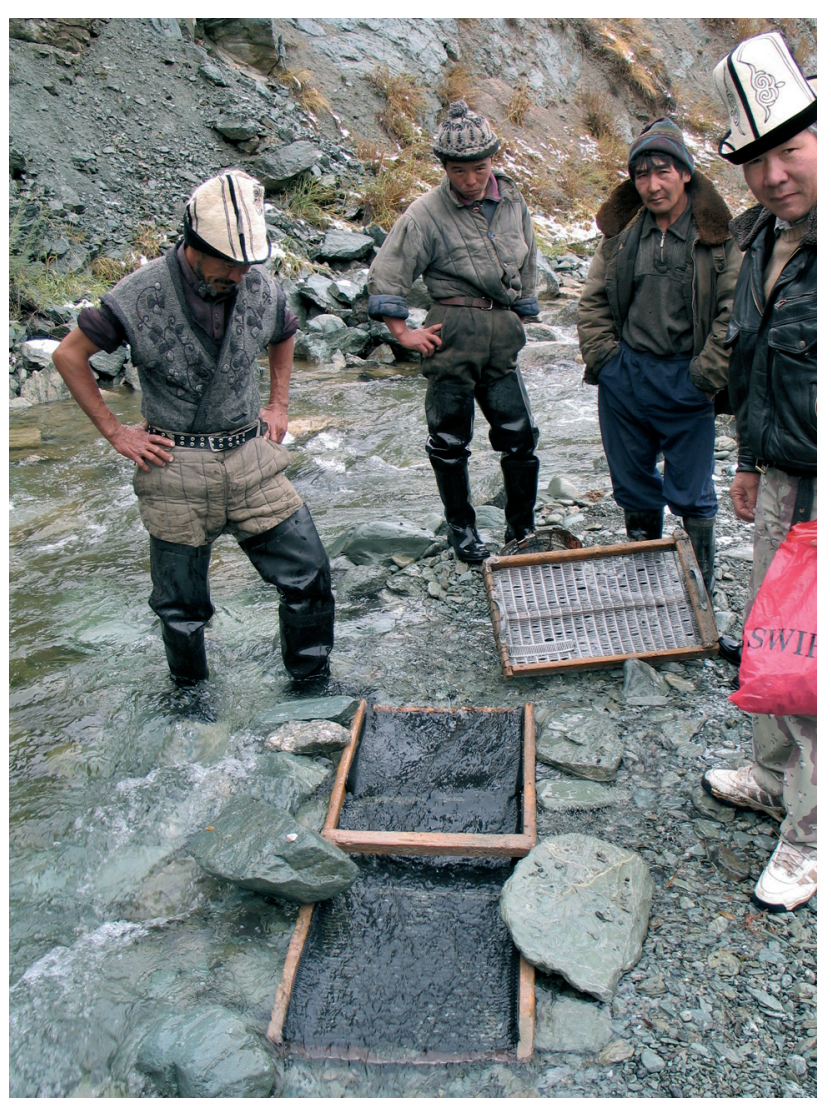

Fig. 1. Sluice for recovering placer gold in a stream in Kyrgyzstan. 


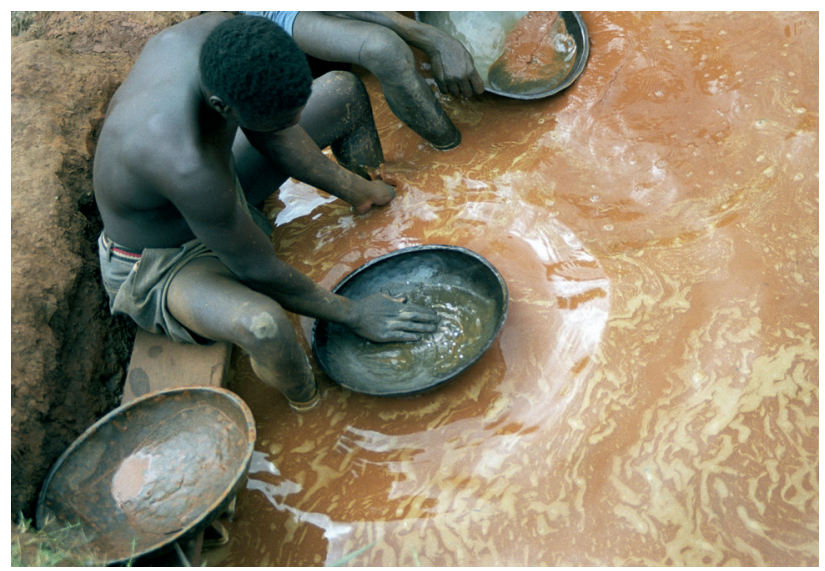

Fig. 2. Amalgamation in Tanzania. Note the shiny spots of metallic mercury in the pan.

The method of using a fleece has, however, largely been replaced by more efficient techniques. Gold has a high specific gravity of $19 \mathrm{~g} / \mathrm{cm}^{3}$, that makes gold easy to concentrate by mechanical means. The traditional gold pan, known from the gold rush in Alaska in the late 1800s, is still one of the most efficient and widespread ways of recovering gold on a small scale. In a gold pan, light minerals such as quartz and feldspar are removed, and the heavy minerals, including grains of gold, are left in the pan. The larger gold grains can be hand-picked from the heavy minerals in the pan, but the fine-grained gold (gold dust) that can account for up to $60 \%$ of the gold may be lost. This is, of course, not very efficient, and the most widely used method to increase the recovery of gold is by amalgamation using mercury (see below).

\section{Small-scale gold mining}

Small-scale mining for gold may be carried out in situ on gold-bearing hard rock, or in gold placer deposits forming riverbeds and riverbanks. Where tunnels are dug into the unconsolidated placer sediments, cave-ins are common and make working conditions very dangerous. The gravel that is extracted is sieved and the heavy minerals are then concentrated in a sluice (Fig. 1). River water flowing through the sluice removes the light minerals, and large gold grains can then be hand-picked and the residue concentrated in a gold pan. This concentrate may again be hand-picked for visible gold grains, or treated with mercury (amalgamation).

Hard rock mining is commonly focussed on gold-bearing quartz veins. Vertical shafts may be sunk down several tens of metres, and a network of tunnels up to hundreds of metres long branching out from the shaft are used to follow the goldbearing veins and excavate the ore. However, even here insufficient support of roofs and walls may result in frequent cave-ins and loss of life. The mined ore is crushed and ground by hand or in small mills. The fine material is then washed in a gold pan, hand-picked, and the residue often treated with mercury.

\section{Amalgamation}

During amalgamation mercury is added to a mineral concentrate (Fig. 2). Gold dissolves in the mercury, forming an amalgam. The amalgam is then placed in an iron cup and heated over an open fire, which evaporates the mercury, and leaves behind the gold.

Amalgamation is a very efficient process for recovering fine-grained gold, but has the disadvantage that large amounts of mercury are released into the environment during the process. In Mongolia alone several tonnes of mercury are released to the environment every year, and the amount released globally reaches many hundreds of tonnes.

\section{Health problems}

Mercury that evaporates during amalgamation condenses on cooling, and often finds its way into local streams and rivers as metallic mercury. Metallic mercury may be converted by bacterial action into the even more toxic methylated mercury. Both forms of mercury readily enter the food chain, and ultimately can lead to severe health problems for human beings.

Even small amounts of mercury affect the nervous system in human beings and cause tremors, while larger amounts can lead to erithism, a mental illness that leaves its victims irritated and very short-tempered. Further stages in mercury poisoning give rise to inflammation in the gingiva, tunnel vision and permanent brain damage. Mercury poisoning is particularly dangerous for pregnant women, as the foetus concentrates mercury selectively relative to the mother by a factor of up to ten. Thus, while a mother may have only slight symptoms of mercury poisoning, the baby may be born with permanent brain damage.

Mercury levels of a population may be easily tested by analysing hair, blood or urine samples.

\section{Recycling of mercury and alternative methods}

Extracting gold by amalgamation has been used for centuries and on most continents. There are thus very large parts of the World which have become polluted, and consequently very many people that suffer from serious mercury poisoning. In South America various measures for recycling mercury have been experimented with, and alternative measures for extracting gold have been developed. 


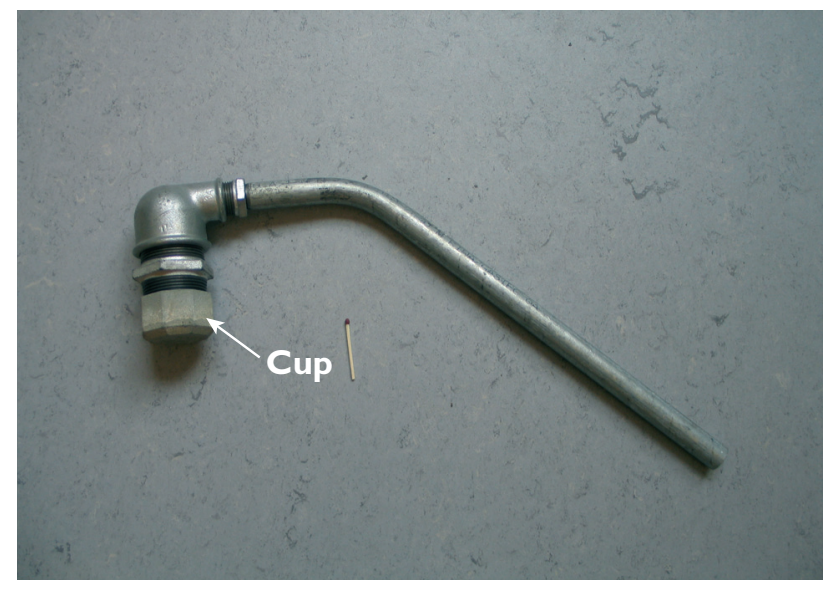

Fig. 3. Retort; the amalgam is placed in the cup that is heated over an open fire. Evaporated mercury is condensed in the pipe and can be collected for recycling. Match for scale.

The most efficient, least expensive and most robust apparatus invented to recycle mercury is the so-called retort. This consists of segments of plumbing tubes joined together. The amalgam is placed in the retort cup on an open fire (Fig. 3). The evaporating mercury escapes into the long thin tube that is cooled by a piece of wet cloth, and condenses back into mercury that is collected in a small glass filled with water. The condensed mercury can then be re-used. Using retorts can reduce the release of mercury to the environment by more than $95 \%$, and the method has been promoted by different organisations, including UNIDO and the World Bank. During World Bank missions in Kyrgyzstan and Mongolia, the author held classes demonstrating how to use the retort (Fig. 4), and distributed retorts to small-scale miners in Mongolia. If mass-produced the cost of the retort is only 5 to

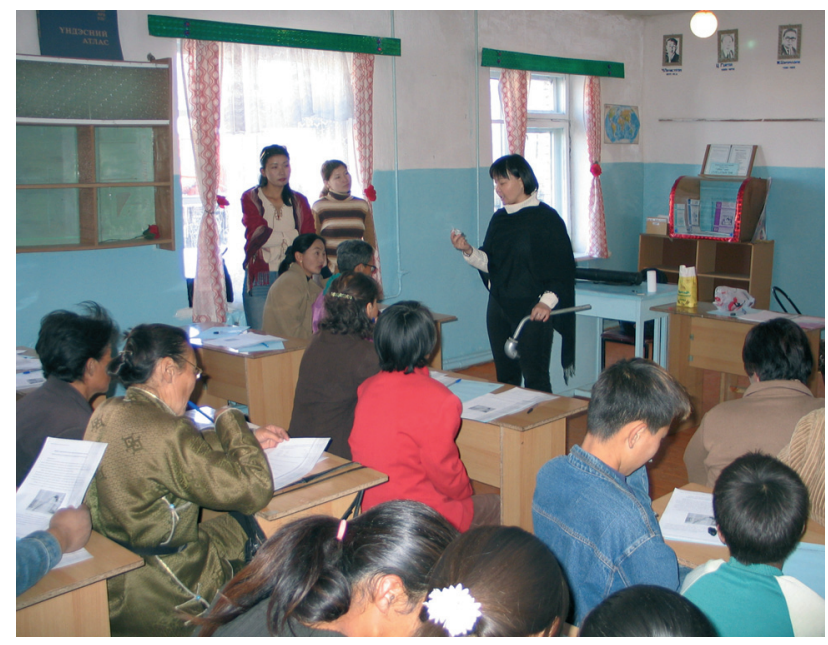

Fig. 4. Teaching small-scale miners in Mongolia to use retorts

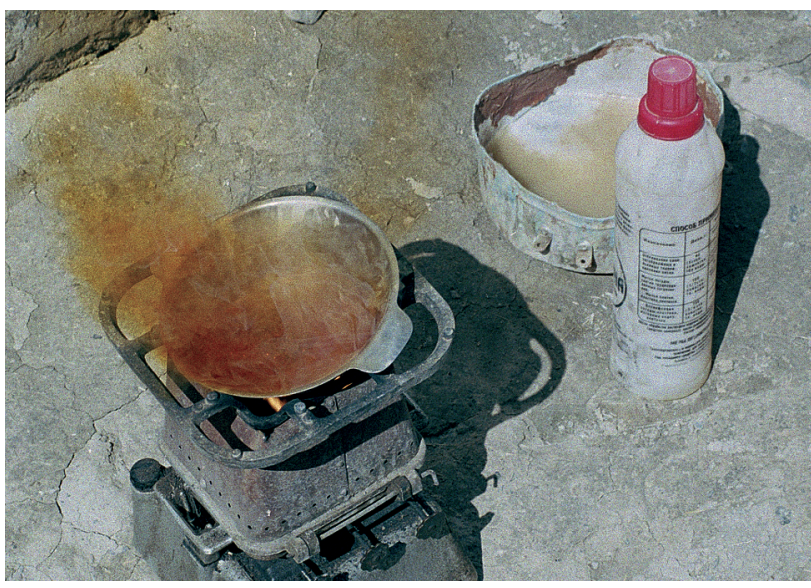

Fig. 5. Acid treatment. Boiling the gold concentrate with concentrated nitric acid. The process releases very toxic brown fumes of nitrogen oxides.

10 Euros, which should allow funding organisations to hand them out to small-scale miners.

Teaching small-scale miners to use retorts is a major advance, but local regulations can prevent its implementation. During a World Bank mission in Kyrgyzstan in 2003, the author suggested that training courses for miners in the use of retorts should be established. The use of mercury is, however, forbidden by law in Kyrgyzstan, and although mercury is actually used, teaching small-scale miners how to use retorts is forbidden. The Mongolian government has a more relaxed attitude. Use of mercury in Mongolia is also forbidden, but teaching about the advantages of using retorts is not.

There are also alternative methods of extracting gold from heavy mineral concentrates from placer deposits. A very simple method, called acid treatment, is used in Kyrgyzstan. The heavy mineral concentrate is dried and treated with a hand magnet that removes all magnetic minerals, leaving only gold and metal sulphides. Concentrated nitric acid is then added and the mixture is heated (Fig. 5); the acid dissolves the sulphides such that only gold is left. Unfortunately, when nitric acid dissolves the sulphides brown fumes of very toxic nitrogen oxides are given off. However, as long as the process is carried out in the open air and away from houses, the toxic gases pose little risk to people. The nitrogen oxides are very unstable and disintegrate rapidly into nitrogen and oxygen.

\section{Sources of mercury}

Mercury is a fairly rare metal, which only occurs in commercial quantities in a few places on Earth. It has been mined for centuries in Spain, Algeria, China and Kyrgyzstan. However, due to the globally declining demand for mercury, many 


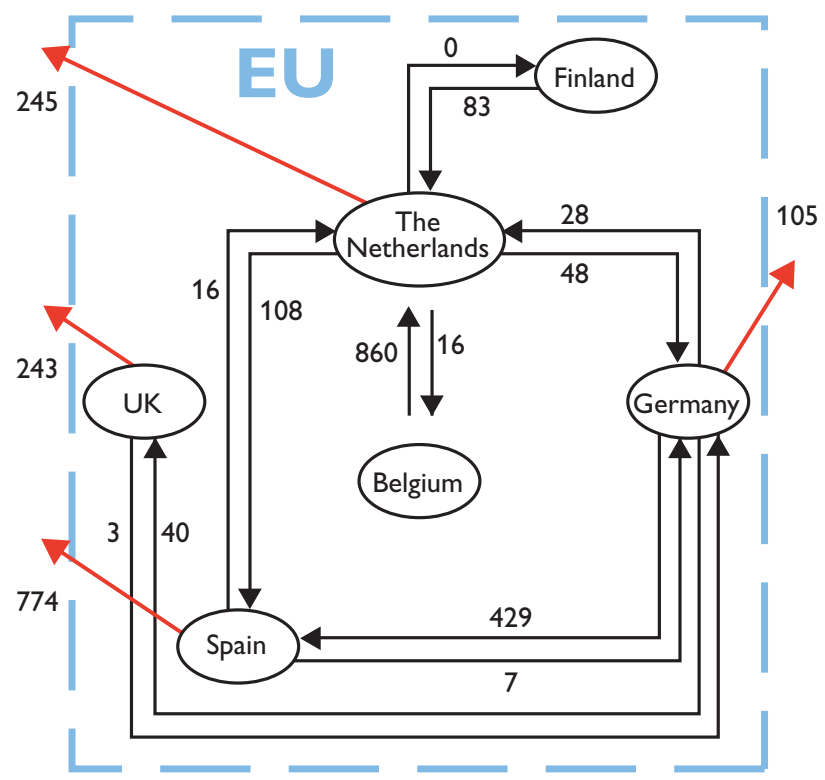

Fig. 6. Mercury trade in the European Union (metric tonnes) in 2000 Red arrows indicate export to mainly Third World countries from the UK, Spain, the Netherlands and Germany.

mercury mines have either been closed down or production has decreased.

Nevertheless, there are apparently almost limitless supplies of cheap mercury available, as mercury has for more than a century been used as a catalyst in the production of chlorine and alkali metals in Europe and North America. Production methods that use mercury as a catalyst have recently been prohibited by the European Union, and European factories have developed less toxic methods. Although the ban on the use of mercury for production purposes does not come into full effect until 2020, many factories have already converted to new techniques. This has created a situation where approximately 50000 tonnes of mercury in Europe are surplus to requirements. Such large quantities pose a major problem for the factories that hold the mercury, and they are actively seeking for ways of disposal.

The current status of mercury trade within Europe and the trade with mercury between Europe and the rest of the World is described by Maxon (2004) in a report for the
European Commission. The mercury trade within the European Union (EU) is illustrated in Fig. 6 which shows that export of mercury from the EU is mainly to Third World countries in Latin America, the Caribbean, South Asia and the Pacific. It is evident that Dutch, English and Spanish companies in particular are helping European factories to dispose of their mercury stocks.

\section{What can be done to help small-scale miners?}

The most efficient way to reduce the health and environmental problems for miners is to teach them either to recycle mercury by using retorts, or to use alternative methods. With that purpose in mind, short teaching and training programmes for small-scale miners in Bornuur township in Mongolia have been carried out showing how to use retorts (Fig. 4). This town is especially appropriate as a target for teaching, since a recent survey has shown that the population in Bornuur has high contents of mercury in urine samples and that the mercury stems from the use of amalgamation by small-scale miners (Tumenbayar 2003). Building on these experiences, further projects are now being considered, including teaching and training medical doctors to diagnose symptoms of mercury poisoning. Included in these programmes would also be the establishment of local information centres where small-scale miners and others can seek information on mercury problems.

The global threat for the environment and health posed by the use of mercury can be reduced considerably and at little cost by teaching and training of miners, and handing out retorts that cost only a few Euros.

\section{References}

Maxon, P. 2004: Mercury flows in Europe and the World: The impact of decommissioned chlor-alkali plants. Brussels: European Commission. Directorate General for Environment, 104 pp.

Tumenbayar, B. 2003: Action research on mercury pollution in Boroo area, Mongolia. Ulaan Baatar, Mongolia: Japan International Cooperation Agency, Mongolia Office, 75 pp. 